\title{
Graphical analysis facilitates evaluation of stream-temperature monitoring data
}

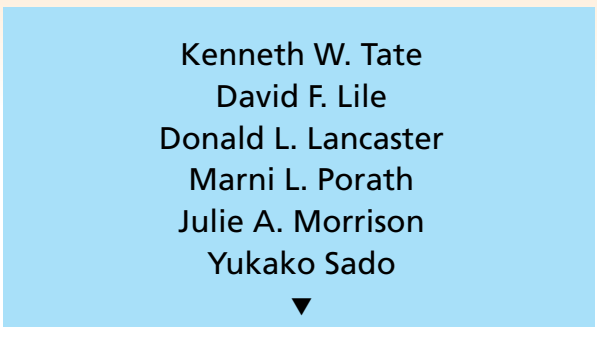

Watershed groups, individuals, and land management and regulatory agencies are collecting streamtemperature data in order to understand, protect and enhance cold-water fisheries. While great quantities of data are being generated, its analysis and interpretation are often not adequate to identify stream reaches that are gaining or losing temperature, or to correlate temperature changes with factors such as vegetative canopy cover or stream-flow levels. We use a case study from the Lassen and Willow creek watersheds in northeastern Modoc County to demonstrate graphical methods for displaying, analyzing and interpreting stream-temperature data.

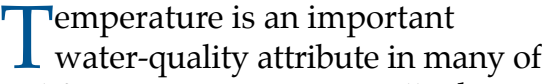
California's streams, especially those that support cold-water salmonids such as trout, steelhead and salmon. Several species of salmonids are threatened or endangered, and elevated stream temperature is often cited as a cause. In rangeland and forest watersheds, summer stream temperatures can be increased by activities such as flow diversion to irrigate pastures, return of warm irrigation runoff to streams, and reduction in riparian canopy cover due to logging and grazing. While extremely high water temperatures (generally over $77^{\circ} \mathrm{F}$ ) can be lethal to salmonids, of equal or greater concern is chronic exposure to sublethal temperatures (generally $67^{\circ} \mathrm{F}$ to $76^{\circ} \mathrm{F}$ ), which can af-

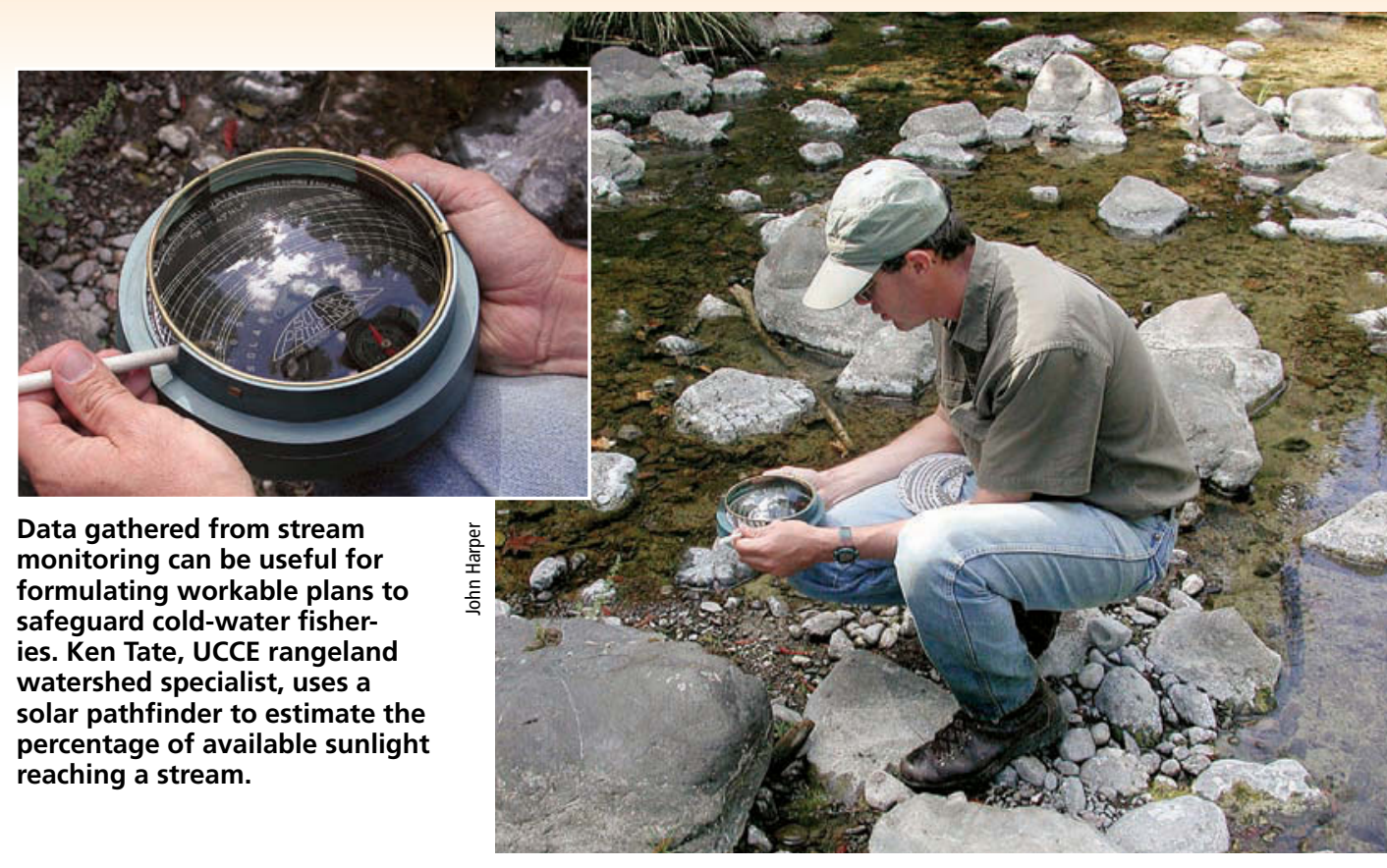

fect their growth, reproductive success and tolerance of pollutants or disease (Sullivan et al. 2000). To reduce stream temperatures and improve cold-water fisheries habitat, water-resource protection agencies have targeted numerous California river systems for the development of watershed-scale restoration plans stating total maximum daily loads (TMDLs). These include nutrients, sediments, pathogens and increases in stream temperature.
Fish responses to temperature vary by species and life stage (such as larval, fry, juvenile and adult; see page 150)(Beschta et al. 1987; Thompson and Larsen 2004). As a result, streamtemperature criteria and objectives to safeguard cold-water fisheries habitat are often dependent upon the species occupying a particular stream reach and the life stage at which the species are present. For example, Oregon's Department of Environmental Quality established

\section{Glossary: stream-temperature metrics}

Daily maximum temperature: Maximum of 48 observations collected every half hour during each 24-hour day.

Daily average temperature: Average of 48 temperature observations collected every half hour during each 24-hour day.

7-day running average of daily maximum temperature: Calculated for each day as average of daily maximum temperature observed for that day and for 6 consecutive prior days.

7-day running average of daily average temperature: Calculated for each day as average of daily average temperature observed for that day and for 6 consecutive prior days.

Maximum weekly maximum temperature: Maximum 7-day running average of daily maximum temperatures observed during a period of interest (such as a specific month or critical fish life stage).

Maximum weekly average temperature: Maximum 7-day running average of daily average temperatures observed during a period of interest. 


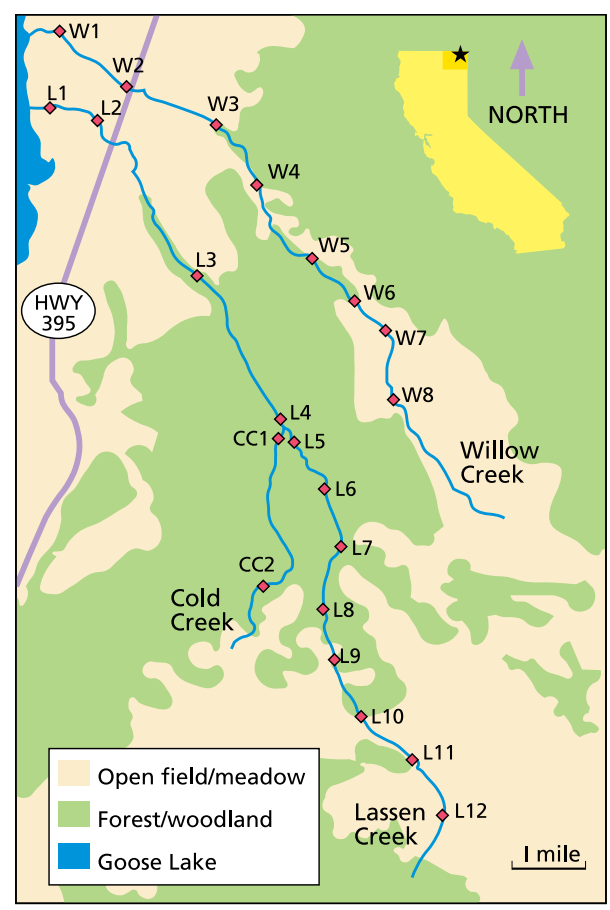

Fig. 1. Stream-temperature monitoring locations on Lassen, Willow and Cold creeks in northeastern Modoc County, Calif.

a standard of $66^{\circ} \mathrm{F}$ as the 7-day moving average of daily maximum stream temperature for general salmonid use, but recommends $55^{\circ} \mathrm{F}$ for spawning, egg incubation and fry emergence.

Monitoring and data collection are frequently undertaken in streams across California and the western United States. The objectives often include: (1) the evaluation of compliance with specific stream-temperature criteria; (2) the determination of temperature changes above and below a land-use activity, through a given property or stream reach, or along an entire stream network; and (3) the examination of watershed-specific associations between stream temperature and factors such as air temperature, stream flow and riparian canopy cover. Several publications provide guidance on how to plan and implement water-quality and streamtemperature monitoring (ODF 1994; MacDonald et al. 1991; US EPA 1997), but few provide guidance on how to analyze and interpret the resulting data.

While the availability of inexpensive, automatic temperature recorders has facilitated data collection, in our experience the sheer volume of data gathered often overwhelms individuals, watershed groups and agencies. As a result, the data is often not analyzed. We have
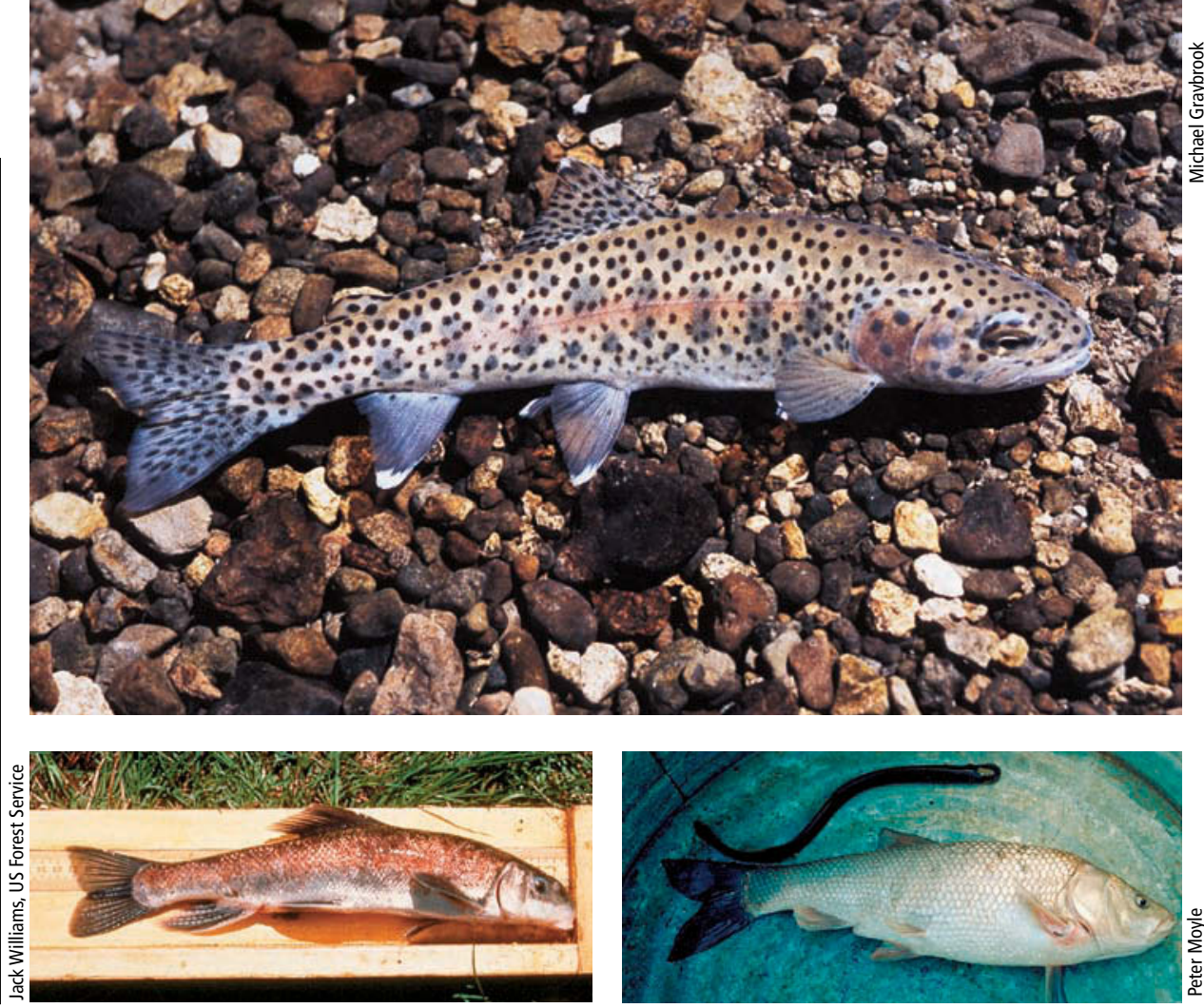

Salmonids and other native fish need cold-water stream habitat to successfully grow, reproduce and tolerate pollutants and disease. In the Goose Lake Basin, native fish requiring such habitat include: top, Goose Lake redband trout; bottom left, Goose Lake sucker; and, bottom right, Goose Lake lamprey (top) and Goose Lake tui chub (bottom).

also observed that when groups collect stream-temperature data, they often neglect to collect data on associated factors (such as air temperature, stream flow, canopy cover and reach length) that are required to fully interpret the streamtemperature data, in order to reach defensible conclusions for management, restoration and regulatory decisions.

The objective of our study was to demonstrate methods for the graphical display and analysis of the kind of stream-temperature data typically collected in monitoring efforts. We illustrate presentation formats and nonstatistical approaches to facilitate the synthesis and interpretation of data for the purposes of monitoring compliance and evaluating the impacts of land-use activities. In the paper that follows (see page 161), we illustrate a statistical approach to analyzing complex sets of stream-temperature data and associated parameters. For both papers, we utilize the same data set, collected during the summers of 1999, 2000 and 2001 across the Lassen and Willow creek watersheds in northeastern Modoc County (in the northeastern-most corner of California).

\section{Lassen and Willow creek watersheds}

Located on the western slope of the Warner Mountains, the Lassen and
Willow Creek watersheds lie parallel to each other, have a northwest aspect and flow directly into Goose Lake, which is at 4,700 feet (fig. 1). The upper reaches of both watersheds are in the Modoc National Forest and extend as high as 6,000 to 7,500 feet. Both streams flow out of predominantly publicly owned (U.S. Forest Service) mountains and into predominantly privately owned valleys and plains above Goose Lake. The public lands are managed for multiple uses including extensive livestock grazing and dispersed recreation. The private lands are used primarily for livestock grazing, as well as irrigated and dryland hay production. We selected these watersheds for study due to the willingness of landowners to cooperate, as well as in response to requests for stream-temperature information driven by local concerns for native fishes that use these streams for spawning and rearing habitat.

Although both streams reach peak runoff with snowmelt in the spring (May through June), they are primarily spring-fed during the summertime base flow (between rain-storm events, before and after snowmelt). Lassen Creek is about 14 miles long and Willow Creek is about 11 miles long. The streams are similar, but do have some clear differences. In Lassen Creek, perennial 

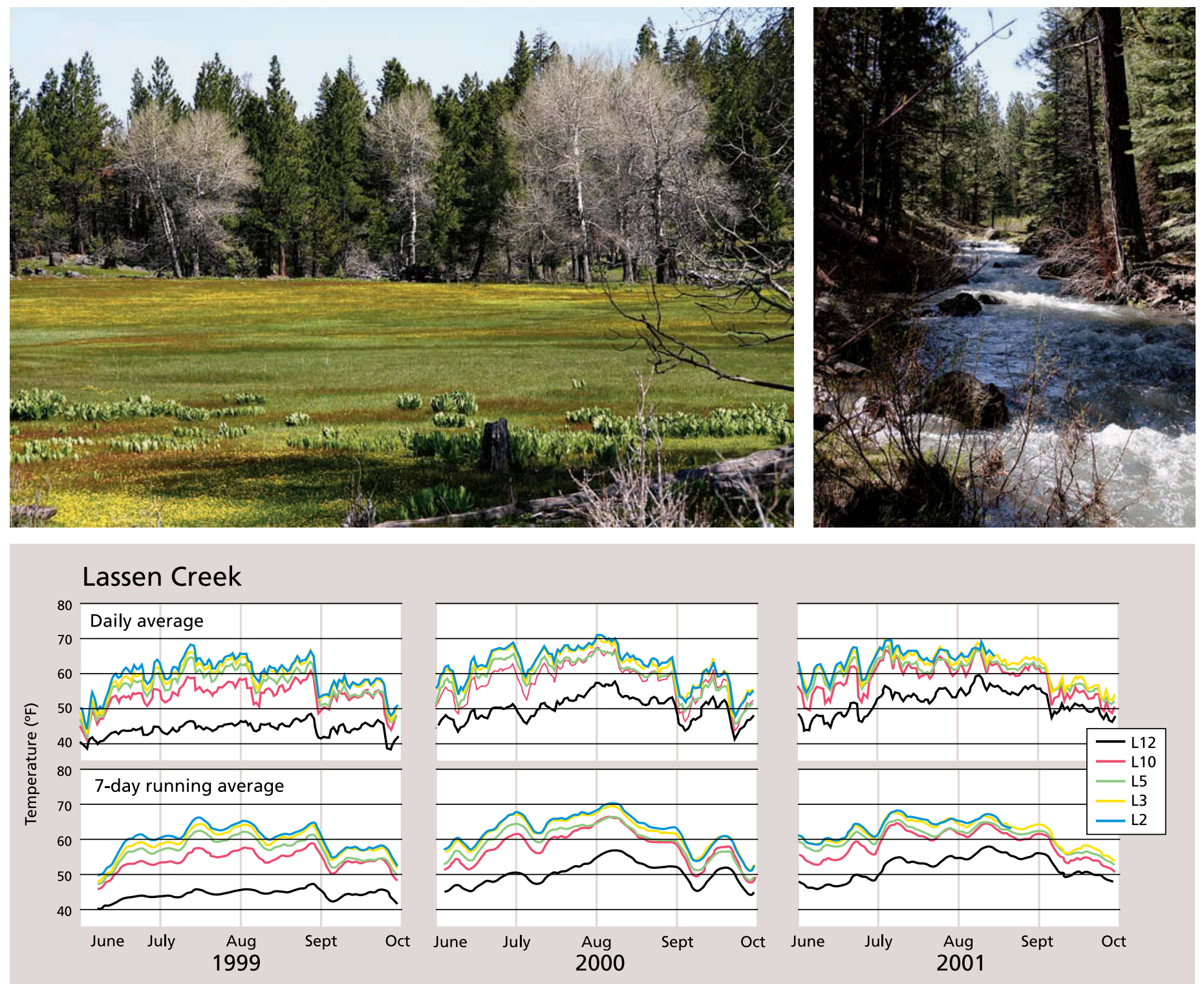

Fig. 2. Daily average and 7-day running average of daily average stream temperature observed at sampling locations, representing the longitudinal profile of Lassen Creek for 1999, 2000 and 2001.

\section{Willow Creek}

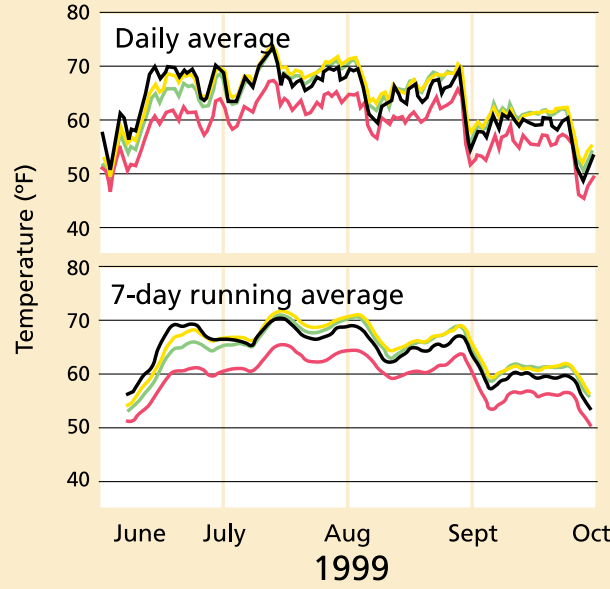

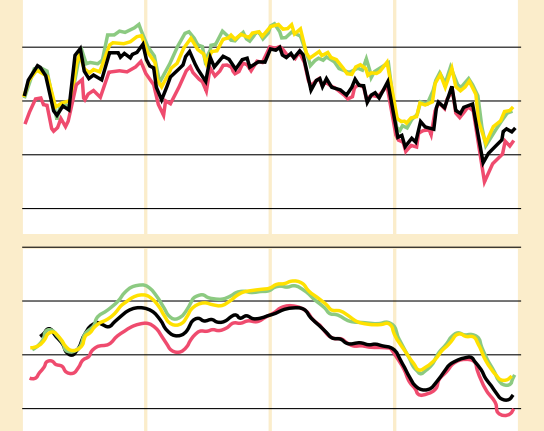

Aug Sept Oct
2000
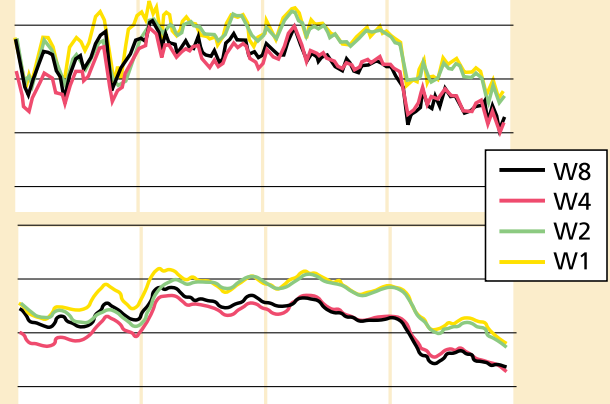

June July $\quad \begin{aligned} & \text { Aug } \\ & 2001\end{aligned}$

Fig. 3. Daily average and 7-day running average of daily average stream temperature observed at sampling locations, representing the longitudinal profile of Willow Creek for 1999, 2000 and 2001. 


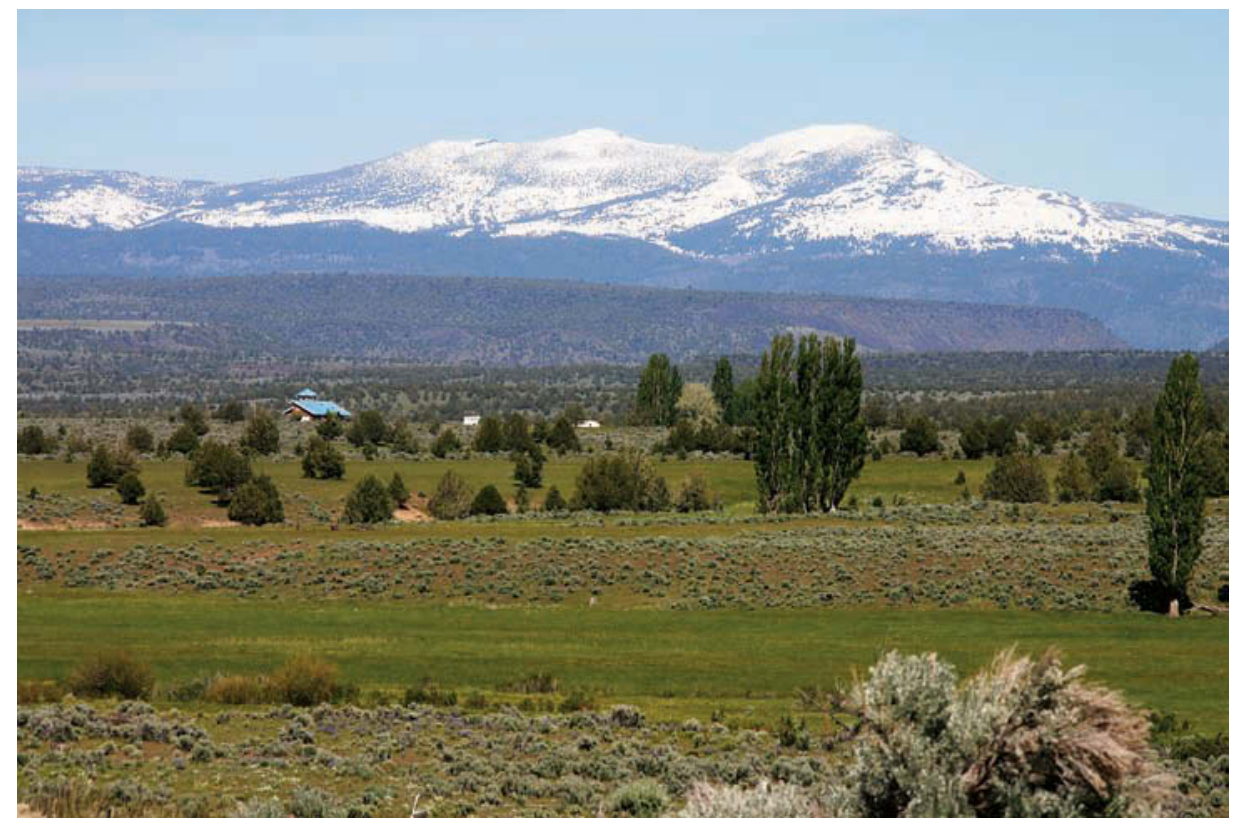

Stream flow is an important factor determining stream temperature, with daily maximum temperatures decreasing as flow increases. Facing page, left, flatter meadows, such as in the Lassen Creek watershed, slow down flow and allow warming; facing page, right, narrow canyon reaches provide natural shade and potentially force the emergence of cool subsurface stream flow. Snowpack in the Warner Mountains, above, feeds Lassen and Willow creeks in the northern range and the Pit River in the southern range (shown).

second (cfs) using the area velocity method (stream width in feet times average stream depth in feet times average stream velocity in feet per second). Stream velocity was measured with a hand-held velocity meter at the same times as water width and depth.

Canopy cover and solar input were measured in July 2000 at five sample locations equally spaced along the 1,000foot stream reach immediately upstream of each monitoring location. Canopy cover - the percentage of sky blocked by vegetation - was measured with a densiometer. Solar input - the percentage of available solar input reaching the stream surface - was measured using a solar pathfinder. Canopy cover at each location was calculated from four densiometer readings taken in the middle of the stream at each location (facing upstream, left bank, downstream, right bank) following California Department of Fish and Game protocol (DFG 1998). Solar input was measured at the same locations as canopy cover with the solar pathfinder held just above the stream surface in the middle of the stream, following standard methods (Platts et al. 1987). The design of the solar pathfinder allows for calculation of monthly solar input from a single reading. Solar input readings are correlated to the vegetative canopy readings but are also affected by stream aspect and topographic features such as canyon walls or nearby mountains, which may block the sun during portions of the day or year.

\section{Temperatures along streams}

Monitoring groups are often interested in comparing stream temperature at specific locations along a stream, for example, on a specific reach (such as L12 versus L10) or along a longitudinal profile from upper to lower stream locations (such as L12 versus L11 versus L10)(fig. 1). This information can be used to identify and prioritize points of concern for fisheries (such as areas exceeding temperature standards), restoration opportunities (such as riparian planting to increase canopy cover) or land-use activities that should be mitigated (such as excessive warm irrigation-water returns).

One way to display and analyze data from monitoring locations along a stream system is to plot temperature at multiple locations over time on the same graph. Figures 2 and 3 synthesize a cumbersome raw data set of 158,112 data points (nine locations, times 3 years, times 122 days per year per location, times 48 readings per day), yet still reveal seasonal trends (such as peak temperatures in August and rapid reduction during the first week of September) that would be lost in monthly, seasonal or annual statistics (such as average and maximum). These figures provide a simple means of illustrating which stream was warmer or colder, and how stream temperature changed through the summer and across years, as well as an initial assessment of how stream temperature changed over time along a given stream reach or system.

For example, we found that Willow Creek was consistently warmer than Lassen Creek, which means that Lassen Creek provided more cold-water habitat than Willow Creek (figs. 2 and 3). Mean stream temperature from the top to bottom of Lassen Creek could increase from $10^{\circ} \mathrm{F}$ to $20^{\circ} \mathrm{F}$ on a given day (L12 versus L2), with the greatest increase in temperature occurring on a reach flowing through a naturally open meadow (between L12 and L10). Willow Creek, on the other hand, cooled as it flowed through a long, shaded canyon reach (between $\mathrm{W} 8$ and $\mathrm{W} 4$ ) and then increased in temperature as it continued downstream. The reduction in stream temperature between locations W8 and W4 on Willow Creek varied by year. Cooling through this reach was greatest in 1999, which had higher stream flows than 2000 and 2001, both years of regional drought and low flow.

For simplicity and clarity, the statistics that best reveal the area of concern should be plotted. The 7-day running average results in a smoother plot that facilitates comparisons among multiple locations. By contrast, if the concern is the acute effects of daily temperature variations, then plotting the daily average or maximum for only one or two sites is more clear and informative.

\section{Comparisons between stream reaches}

While graphics such as figures 2 and 3 allow for the efficient display and initial interpretation of the large, raw data sets typically collected by stream-temperature monitoring efforts, additional data reduction and graphical analysis are required to compare the change in stream temperature occurring between different reaches. With limited budgets for 
